\title{
Bicelin (B-cell lymphoma 2 inhibitor) a Highly Safe DNA-based Anti-cancer Drug Showed No in vivo Cytopenia, Nephrotoxicity and/or Hepatotoxicity
}

Reza Sheikhnejad ( $\nabla$ sheikhnejad@msn.com )

Oshida Novel Pharmatech https://orcid.org/0000-0003-0342-4960

Farzaneh Ashrafi

Isfahan University of Medical Sciences

Ardeshir Talebi

Isfahan University of Medical Sciences

Bahar Mazaheri

Isfahan University of Medical Sciences

\section{Fatemeh Moslemi}

Isfahan University of Medical Sciences

Mehdi Nematbakhsh

Isfahan University of Medical Sciences

Research article

Keywords: Bicelin, B-cell lymphoma 2 (BCL-2), Nephrotoxicity, Hepatotoxicity

Posted Date: October 30th, 2020

DOl: https://doi.org/10.21203/rs.3.rs-97298/v1

License: (c) (i) This work is licensed under a Creative Commons Attribution 4.0 International License.

Read Full License 


\section{Abstract}

Background: Non-Hodgkin's lymphoma is the seventh most common cancer in clinic. Lymphoma could be treated with newly developed anti-apoptotic small molecule inhibitors of bcl-2 such as ABT-199 or venetoclax. However most small molecules present numerous side effects and cancer becomes resistance to them rapidly. PNT100 is a DNA-based bcl-2 inhibitor that has shown great efficacy and safety in treating non-Hodgkin's lymphoma tumors. However, liposomal carrier(smarticles) that was used to deliver PNT100 eventually failed to produce robust efficacy in the latest clinical trial conducted by ProNai Therapeutics (now called Sierra Technology). The high cost of liposomal carriers, makes this targeted drug less affordable. In addition, the liposomal components may also present some minor side effects as reported in pilot phase II trial [17-22]. In this study, we eliminated liposome and used a specific Epigenic modification to deliver this $24 \mathrm{bp}$ oligonucleotides (PNT100) without using additional chemicals and named it Bicelin.

Methods: In this study, the safety of Bicelin was determined by evaluating the cytopenia, nephrotoxicity and hepatotoxicity effects of this drug in healthy animal model (Rats). The rats in experimental group were received Bicelin $(20 \mathrm{mg} / \mathrm{kg} /$ day) for 5 days a week. The treatment was continued for 3 consecutive weeks. The blood and urine samples were collected for evaluation and the rats were then sacrificed. The kidneys and liver tissues were fixed in formalin $10 \%$ to perform histological investigation using H\&E staining.

Results: The in vitro and in vivo results clearly demonstrate that Bicelin is target specific and highly safe. We observed no cytopenia when blood tests were performed after 15 consecutive injection of Bicelin; Urine analysis revealed no significant differences between experimental and control group and there was no nephrotoxicity or hepatotoxicity when kidney and liver tissues were examined.

Conclusion: based on our in vitro and in vivo safety studies, our bcl2 inhibitor, Bicelin is much safer and about 10 -fold more effective than its liposomal form (PNT2258). Considering preclinical, phase I and II studies of PNT2258, Bicelin is expected to be very safe and effective in clinic.

\section{Background}

Apoptosis is a regulated programmed cell death that is triggered in defected cells. This selective cell suicide plays an essential role in numerous physiological and pathological processes [1]. There are two apoptotic pathways-the extrinsic pathway (activated by ligand engagement of cell surface death receptors) and the intrinsic (mitochondrial) pathway. The BCL-2 family of proteins regulate activation of the intrinsic apoptotic pathway in response to cellular stresses such as DNA damage, g-irradiation, oncogene activation etc.

BCL-2, was first identified through chromosomal mapping in follicular lymphoma where constitutive BCL2 expression is driven from the immunoglobulin locus by the $t[14 ; 18]$ translocation [2-4]. BCL-2 facilitate oncogenesis through cell death resistance $[5,6]$. Its involvement in $t(14 ; 18)$ in follicular lymphoma $(F L)$, 
has a central role in the inhibition of apoptosis. The t $(14 ; 18)$ translocation causes constitutive overexpression of BCL2 by juxtaposing it to immunoglobulin heavy chain gene enhancer elements. This translocation is found in $20 \%$ of DLBCL. In the following years over15 proteins have been added to this family, each containing one or more BCL-2 homology $(\mathrm{BH})$ domain. Bcl-2-family proteins play central roles in cell death regulation and are capable of regulating diverse cell death mechanisms that encompass apoptosis, necrosis and autophagy $[7,8]$.

In addition to chromosomal translocations as a mechanism for activation of the BCL-2 gene in human malignancies, changes to BCL-2 gene structure or copy number and many additional mechanisms contribute to elevated gene expression, which is estimated to occur in perhaps as many as half of all human cancers. Among the contributing mechanisms are (a) loss of endogenous microRNAs (miRs) that normally repress BCL-2 gene expression which has been documented in chronic lymphocytic leukemia, where the genes encoding miR15 and miR1 6 become deleted or inactivated by mutations in $>70 \%$ of these leukemia, and gene hypomethylation, implying altered epigenetic regulation of BCL-2 in some malignancies $[9,10]$.

Non-Hodgkin's lymphoma is the seventh most common cancer in clinic [11]. lymphoma can be treated with anti-apoptotic small molecule inhibitors of bcl-2 such as ABT-199 or venetoclax. However, small molecules generally present numerous side effects moreover, cancer becomes resistance to them after a month or two. Therefore, they offer no long-term solution or survival. Interfering with mRNA activities using RNAi could provide another alternative therapy as well [12-15]. It is well documented that the BCL2 inhibitor drugs such as PNT2258 have beneficial effects in solid and non-Hodgkin's lymphoma tumors. The PNT2258 is a single-stranded DNA monocyclic phosphodiesterase contain a liposomal coating (SMARTICLE) which has therapeutically purpose via inhibition of BCL-2 [16]. The PNT2258 has antitumor activity in the xenograft models and has been safe and tolerant in Phase I clinical studies and has been reported as a highly effective drug in a pilot phase II clinical trials in patients with resist and recurrent non-Hodgkin's lymphoma [17-22].

However, there are limitations using this BCL-2 inhibitor drug, PNT2258. First, the high cost of liposomal carriers makes it less affordable; secondly, the drug delivery may not be efficient due to leaking and/or inefficient release of oligonucleotides in cytoplasm. Third, the liposomal components may also present some minor side effects such as thrombocytopenia (low count of platelets) and lymphocytopenia (low count of lymphocytes) as well as fatigue as reported in pilot phase II trial [17-22].

In this study, the liposomal coating of PNT100 has been dismissed and the DNA-based BCL-2 inhibitor has been delivered using novel Epigenic modification (confidential information). Therefore, Bicelin is being delivered directly without other compounds or chemicals as delivery system. Here, we first determine the in vitro cytotoxicity of Bicelin and then, evaluating its in vivo cytopenia, nephrotoxicity and hepatotoxicity effects of this drug in healthy animal model (Rats).

\section{Methods}




\section{Bicelin drug}

PNT100 is a single-stranded DNA, 24-base oligonucleotide that has been designed by our colleague, Dr. Reza Sheikhnejad using DNAi technology with over 20 international patents. This 24-base nucleotide was chemically synthesized on a solid phase column, cleaved and purified using HPLC. It was then freezedried before use. This oligonucleotide is designed specifically to regulate the activity of BCL2 but has no effect on other members of BCL2 family such as Bcl-xl, MCL-1 or Bcl-w (11). The 24-base oligo is designed to hybridizes within untranscribed regulatory region of BCL2 thus interferes with oncogene transcription.

\section{In vitro anti-cancer activity assay}

Cancer cells, DLBCL (diffuse large B-cell lymphoma) were purchased from ATCC (LGC Standards, Gmbh, Germany). The cells were seeded at 5,000 cells/well/200 $\mu$ in a 96-well plate and the culture was maintained in RPMI 1640 supplemented with $10 \%$ fetal bovine serum, $1 \%$ L-glutamine, 100 units $/ \mathrm{mL}$ penicillin, and $100 \mu \mathrm{g} / \mathrm{mL}$ streptomycin overnight. The media was replaced with fresh media containing plant extracts and incubated for $48 \mathrm{~h}$ in a humidified atmosphere of $95 \%$ air and $5 \% \mathrm{CO} 2$ at $37^{\circ} \mathrm{C}$ until the control cultures were confluent. The media was then removed and the plate was washed two times with phosphate-buffered saline (PBS). Serum-free media $(100 \mu \mathrm{L})$ containing $0.5 \mathrm{mg} / \mathrm{mL}$ MTT dye was added into each well and incubated at $37^{\circ} \mathrm{C}$ for $2 \mathrm{~h}$. The media with dye was removed, washed with PBS and the reactive dye was solved by addition of $100 \mu \mathrm{l}$ dimethyl sulfoxide (DMSO). The absorbance was read using an automatic plate-reader. All experiments were performed in triplicates.

\section{Animal experiment}

Ten, 3 months old male Wistar rats $(279 \pm 10 \mathrm{~g})$ were purchased from the animal house of Isfahan University of Medical Sciences. The animals were housed at the room temperature of $23-25^{\circ} \mathrm{C}$. The rats had free access to water and chow. All procedures were approved by the Ethical Committee of Isfahan University of Medical Sciences. The rats were randomly divided into two groups named control and experimental group. The rats in experimental group were received Bicelin $(20 \mathrm{mg} / \mathrm{kg} / \mathrm{day})$ for 5 days a week. The treatment was continued for 3 consecutive weeks. The control group was treated with saline only. At the end of 3 weeks, the animals were placed in metabolic cages for 4 hours to collect their urine.

Finally, the blood samples were collected and the rats were then sacrificed following the University approved ethical procedure. Briefly, the animals were anesthetized with chloral hydrate $(450 \mathrm{mg} / \mathrm{kg}$, intraperitoneally) (Merck, Germany). The, kidneys and liver tissues were fixed in formalin $10 \%$ to perform histological investigation using H\&E staining. The kidney and liver tissues damage score (KTDS, LTDS) were recorded by two pathologist who were blinded to the study protocol. The score was assigned from 1 to 4 based on intensity of tissue damage while zero was considered as normal.

The blood samples were subjected to cell blood count (CBC). The serum levels of blood urea nitrogen (BUN) and creatinine $(\mathrm{Cr})$, sodium $(\mathrm{Na})$, potassium $(\mathrm{K})$, aspartate aminotransferase (AST) alanine aminotransferase (ALT) and anaplastic lymphoma kinase (ALK) also were determined The Cr clearance 
$(\mathrm{ClCr})$ was determined using clearance formula as; $\mathrm{ClCr}=\mathrm{UF} * \mathrm{U}_{\mathrm{Cr}} / \mathrm{P}_{\mathrm{Cr}}$ where $\mathrm{UF}, \mathrm{U}_{\mathrm{Cr}}$ and $\mathrm{P}_{\mathrm{Cr}}$ were assigned as urine flow rate, urine $\mathrm{Cr}$ concentration and serum level of $\mathrm{Cr}$.

\section{Statistical Analysis}

Data were reported as mean \pm SEM. The t-Student test was applied for comparison between the groups. The KTDS between the groups were compared by non-parametric tests of Mann-Whitney U. The statistical $P$ value was significant when it was less than 0.05 .

\section{Results}

The in vitro result (Fig. 1) shows greater ( $\geq 8$ fold) anti-cancer activity for Bicelin compare to liposomal PNT100 (PNT2258). The IC50 is calculated to be less than $10 \mu \mathrm{g} / \mathrm{ml}(\sim 1 \mu \mathrm{M})$. Figure 2 shows that Bicelin is highly specific; it has little effect on lung and pancreatic cancer cells (10-15\%) and a modest in vitro activity on colon cancer (45\%). But bcl2 inhibition seems to be most effective against diffuse large cell lymphoma which is known to have bcl-2 $\mathrm{t}(14 ; 18)$ translocation (Fig. 3). Bicelin had almost no effect on normal cells (fibroblast cell line).

The blood test results demonstrated in table 1 indicate that most blood parameters including hemoglobin level were not significantly different when Bicelin treated rats were compared to the control group receiving only saline. We also observed no weight loss in rats receiving high dose of Bicelin after 15 consecutive injections (Fig. 1). The kidney weight (KW), serum levels of blood urea nitrogen (BUN), creatinine (Cr), aspartate aminotransferase (AST) alanine aminotransferase (ALT) and anaplastic lymphoma kinase (ALK), and urine flow (UF), Cr clearance (CICr), and sodium (ENa) and potassium (EK) excretion fraction in two groups of animal treated with vehicle (control) and Bicelin. No significant differences were observed between the two groups measuring these parameters (Fig. 4).

The pathological examination further proves the safety of our test compound, Bicelin. Figures $5 \& 6$ show no kidney and liver tissue damages induced by Bicelin administration. These findings revealed that Bicelin is highly safe and has no toxicity effects on kidney and liver organs.

\section{Discussion}

The results clearly demonstrate that bcl 2 targeted Bicelin presents no toxicity when tested in vitro using several cancer cells as well as healthy fibroblast cells. Knowing that cell lines have zero tolerability for any toxic materials. Furthermore, the in vitro results also show that Bicelin is highly specific because it has little effect on lung and pancreatic cancer cells (10-15\%) and a modest in vitro activity on colon cancer (45\%). Although bcl2 chromosomal translocation may happens in 10 to $20 \%$ of most cancers, but bcl2 inhibition seems to be most effective in non-Hodgkin lymphoma, diffuse large cell lymphoma (DLCL). The in vivo safety evaluation further indicated that Bicelin is highly safe and we expect no or very little side effect if tested in clinic. Table 1 as well as Figs. 4-6 data profoundly proves our safety speculation. The in vivo results become more significant, considering that the rats were injected 15 
consecutive time with no rest at a dose almost 20 times that of used in clinical trial. The greatest advantage of using Bicelin rather than standard drugs used according to R-CHOP protocol, would be in dosing schedule. There may be no need to interrupt the treatment after each cycle because of low blood cell counts (neutropenia or leukopenia) as well as low platelet count (thrombocytopenia) and low red blood count (anemia) that happen because of chemotherapy's effect on blood cells made in the bone marrow. Blood cell counts often reach their lowest level about 7 to 14 days after chemotherapy. Low blood cell counts is the most common and most serious side effect of chemotherapy. When it happens, the dose of chemotherapy is adjusted and the treatment is delayed until cytopenia improved. increases the risk for infection. The Bicelin in vivo safety results show absolutely no change in blood cell counts. Therefore, we anticipate no interruption in patient treatment and the dose $120 \mathrm{mg} / \mathrm{m}^{2}$ as determined in phase I clinical trial of PNT2258, can be escalated if needed. In conclusion, based on our in vitro and in vivo safety studies, our bcl 2 inhibitor, Bicelin is much safer and about 10 -fold more effective than its liposomal form (PNT2258). Considering preclinical, phase I and II studies of PNT2258, Bicelin is expected to be very safe and effective in clinic.

\section{Conclusion}

Bicelin, a modified DNA oligonucleotide (24 bp), with strong anticancer activity is proven to be extremely safe. After 15 consecutive iv injections, no cytopenia, hepatotoxicity or nephron toxicity was observed in rats. We expect, promising efficacy with little or no side effects when tested in clinic.

\section{Abbreviations}

PNT, ProNai Therapeutics; DLCL, diffuse large cell lymphoma; IC50, the half maximal inhibitory concentration.

\section{Declarations}

- Ethics approval and consent to participate: Animal study protocol was approved by ethic committee of Isfaham University of Medical Sciences.

- Consent for publication: all authors have given their permission to publish the result of this study.

- Availability of data and materials: The data and materials of in vitro study is available at Oshida Novel Pharmatech and the in vivo data is available at ${ }^{3}$ Department of Clinical Pathology, Isfahan University of Medical Sciences, Isfahan, Iran.

- Competing interests: N/A

- Funding was provided by Oshida Novel Pharmatech (owned by corresponding author, RS). The corresponding author who is also the funding body, is the inventor, has developed and formulated the drug, has designed and written the original protocol and has written this manuscript.

- Authors' contributions: First author, RS. Has developed and formulated the experimental drug for this study, and carried out the in vitro tests as well. The second author, FA. Has directed the animal study 
study and helped to design the protocol. The co-author, $\mathrm{MN}$ has designed and supervised the animal study; AT, has performed the pathology; BM and FM have carried out the animal study.

- Acknowledgements: The authors thank Ms Fatemeh Eshragh-Jazi for her technical assistance.

\section{References}

1. Meier P, Finch A, Evan G. 2000 Apoptosis in development. Nature 407, 796 - 801. (doi:10.1038/ 35037734)

2. Tsujimoto Y, Finger LR, Yunis J, Nowell PC, Croce CM. 1984 Cloning of the chromosome breakpoint of neoplastic B cells with the $t(14 ; 18)$ chromosome translocation. Science 226,1097 - 1099. (doi:10. 1126/science.6093263)

3. Bakhshi A, Jensen JP, Goldman P, Wright JJ, McBride OW, Epstein AL, Korsmeyer SJ. 1985 Cloning the chromosomal breakpoint of $\mathrm{t}(14 ; 18)$ human lymphomas: clustering around $\mathrm{JH}$ on chromosome 14 and near a transcriptional unit on 18. Cell 41, 899- 906. (doi:10.1016/S0092-8674(85)80070-2)

4. Cleary ML, Sklar J. 1985 Nucleotide sequence of a t(14;18) chromosomal breakpoint in follicular lymphoma and demonstration of a breakpoint cluster region near a transcriptionally active locus on chromosome 18. Proc. Natl Acad. Sci. USA 82, 7439- 7443. (doi:10.1073/pnas.82.21.7439)

5. Vaux DL, Cory S, Adams JM. 1988 Bcl-2 gene promotes haemopoietic cell survival and cooperates with c-myc to immortalize pre-B cells. Nature 335, 440- 442. (doi:10.1038/335440a0)

6. Hockenbery D, Nunez G, Milliman C, Schreiber RD, Korsmeyer SJ. 1990 Bcl-2 is an inner mitochondrial membrane protein that blocks programmed cell death. Nature 348, 334-336. (doi:10.1038/348334a0).

7. Cory S, Huang DC, Adams JM. (2003). The Bcl-2 family: roles in cell survivaland oncogenesis. Oncogene 22: 8590-8607.

8. Levine B, Kroemer G. (2008). Autophagy in the pathogenesis of disease. Cell 132: 27-42.

9. Cimmino A, Calin GA, Fabbri M, lorio MV, Ferracin M, Shimizu M et al. (2005). miR-15 and miR-16 induce apoptosis by targeting BCL2. Proc Nat Acad Sci USA 102: 13944-13949.

10. Hanada M, Delia D, Aiello A, Stadtmauer E, Reed J. (1993). Bcl-2 gene hypomethylation and high-level expression in B-cell chronic lymphocytic leukemia. Blood 82: 1820-1828.

11. Evens AM, Winter JN, Gordon LL, Chiu BCH, Tsang R, Rosen ST. Cancer management: a multidisciplinary approach medical, surgical, \& radiation oncology. Cancer Management. 2014 from: http://www.cancernetwork.com/cancer-management/non-hodgkin-lymphoma

12. Souers AJ, Leverson JD, Boghaert ER, Ackler SL, Catron ND, Chen J, Elmore SW. ABT-199, a potent and selective BCL-2 inhibitor, achieves antitumor activity while sparing platelets. Nat Med. 2014;19:202-208.

13. Wang G, Nikolovska-Coleska Z, Yang CY, Wang R, Tang G, Guo J, Wang S. Structure-Based Design of Potent Small-Molecule Inhibitors of Anti-Apoptotic Bcl-2 Proteins. Journal of Medicinal Chemistry. 2006;49:6139-6142. 
14. Tse C, Shoemaker AR, Adickes J, Anderson MG, Chen J, Jin S, Elmore SW. ABT-263: a potent and orally bioavailable Bcl-2 family inhibitor. Cancer Res. 2008;68:3421-3428.

15. Al-Katib AM, Sun Y, Goustin AS, Azmi AS, Chen B, Aboukameel A, Mohammad RM. SMI of Bcl-2 TW37 is active across a spectrum of B-cell tumors irrespective of their proliferative and differentiation status. J Hematol Oncol. 2009;2:8.

16. Rodrigueza WV, Woolliscroft MJ, Ebrahim AS, Forgey R, McGovren PJ, Endert G, Al-Katib A. Development and antitumor activity of a BCL-2 targeted single-stranded DNA oligonucleotide. Cancer Chemother Pharmacol. 2014;74:151-166.

17. Harb W, Lakhani N, Logsdon A, Steigelman M, Smith-Green H, Gaylor S, Messmann RA. The BCL2 targeted deoxyribonucleic acid inhibitor (DNAi) PNT2258 is active in patients with relapsed or refractory non-Hodgkin's lymphoma;.2013; Paper presented at the American Society of Hematology Annual Meeting.

18. Tolcher AW, Rodrigueza WV, Rasco DW, Patnaik A, Papadopoulos KP, Amaya A, Messmann RA. A phase 1 study of the BCL2-targeted deoxyribonucleic acid inhibitor (DNAi) PNT2258 in patients with advanced solid tumors. Cancer Chemother Pharmacol. 2014;73:363-371.

19. AS Ebrahim, M Kandouz, A Liddane, H Sabbagh,et al. PNT2258, a novel deoxyribonucleic acid inhibitor, induces cell cycle arrest and apoptosis via a distinct mechanism of action: a new class of drug for non-Hodgkin's lymphoma. Oncotarget. 2016 Jul 5; 7(27): 42374-42384.

20. WA Harb, N Lakhani, A Logsdon, M Steigelman,et al. The BCL2 Targeted Deoxyribonucleic Acid Inhibitor (DNAi) PNT2258 Is Active in Patients with Relapsed or Refractory Non-Hodgkin's Lymphoma. Am Soc Hematology. 2014.

21. Adams JM, Cory S (2007) Bcl-2-regulated apoptosis: mechanism and therapeutic potential. Curr Opin Immunol 19(5):488-496.

22. AW Tolcher, WV Rodrigueza, DW Rasco, et al. A phase 1 study of the BCL2-targeted deoxyribonucleic acid inhibitor (DNAi) PNT2258 in patients with advanced solid tumors. Cancer Chemother Pharmacol. 2013.

\section{Table}

Due to technical limitations, table PDF is only available as a download in the Supplemental Files section.

\section{Figures}




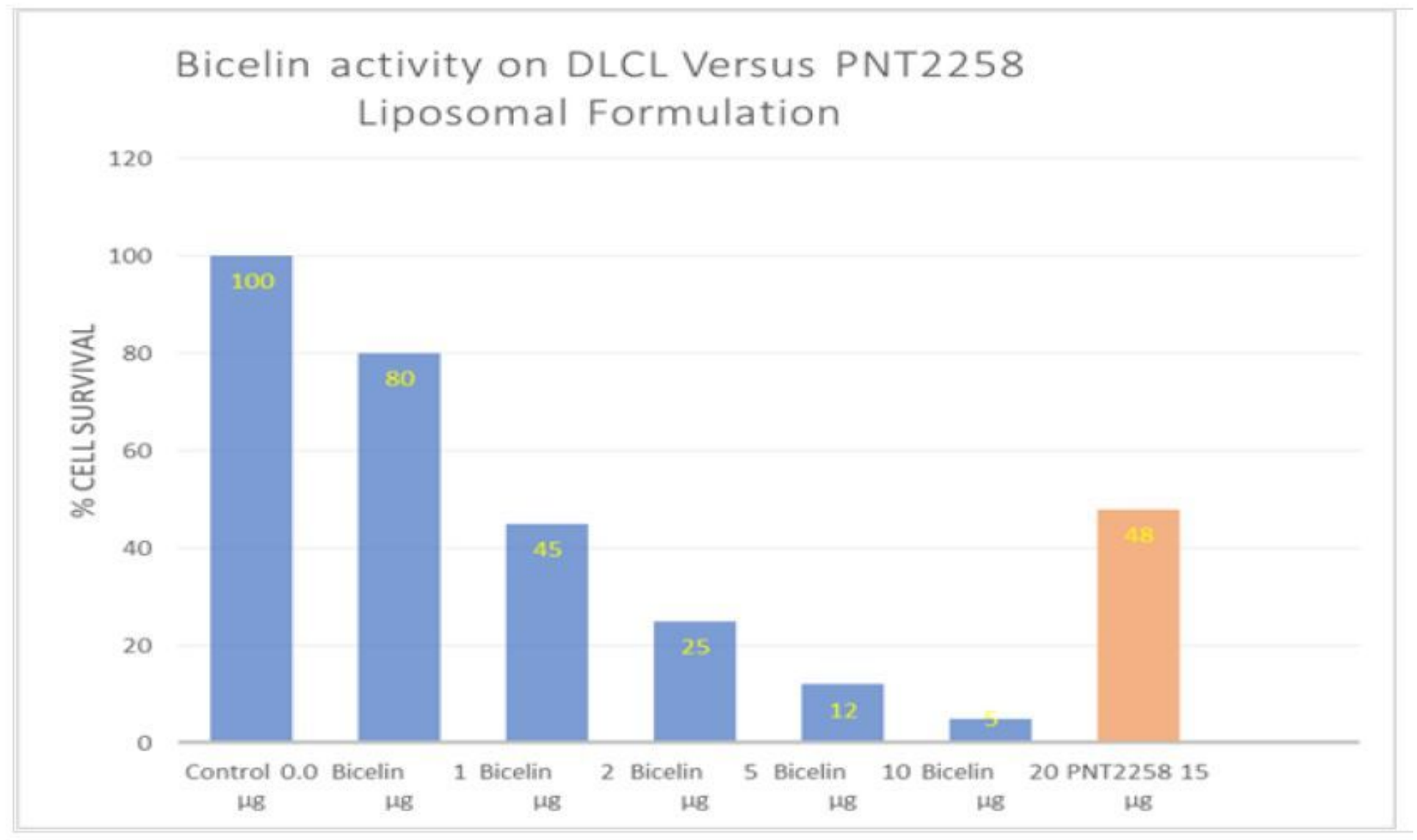

\section{Figure 1}

The Anti-cancer activity of our BCL2 inhibitor Bicelin. The dose response curve shows much greater efficacy for Bicelin compare to PNT2258 (Nano liposomal formulation) prepared by Polymun company in Austria. The IC50 is determined to be less than $2 \mu \mathrm{g}(\sim 1 \mu \mathrm{M})$. 


\section{Anti-Cancer activities of Biclin Versus Cisplatin}

120

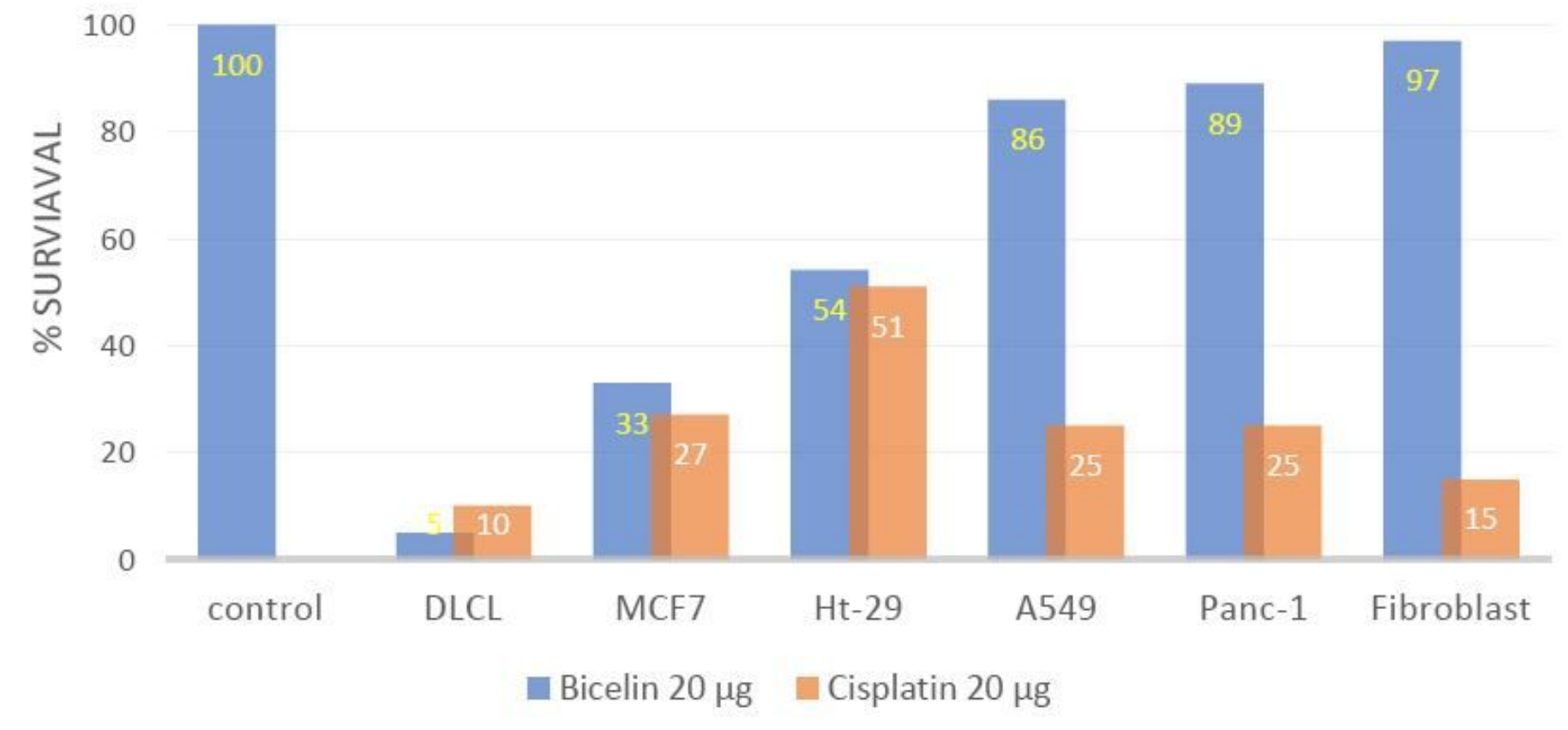

\section{Figure 2}

The Anti-cancer activities of our BCL2 inhibitor (Bicelin) compared to cisplatin anti-cancer activities on DLCL (diffuse large cell lymphoma), MCF7 (breast cancer cells), HT-29 (colon cancer cells), A549 (lung cancer cells), PANC-1 (pancreatic cancer cells) and fibroblast (healthy cells). 


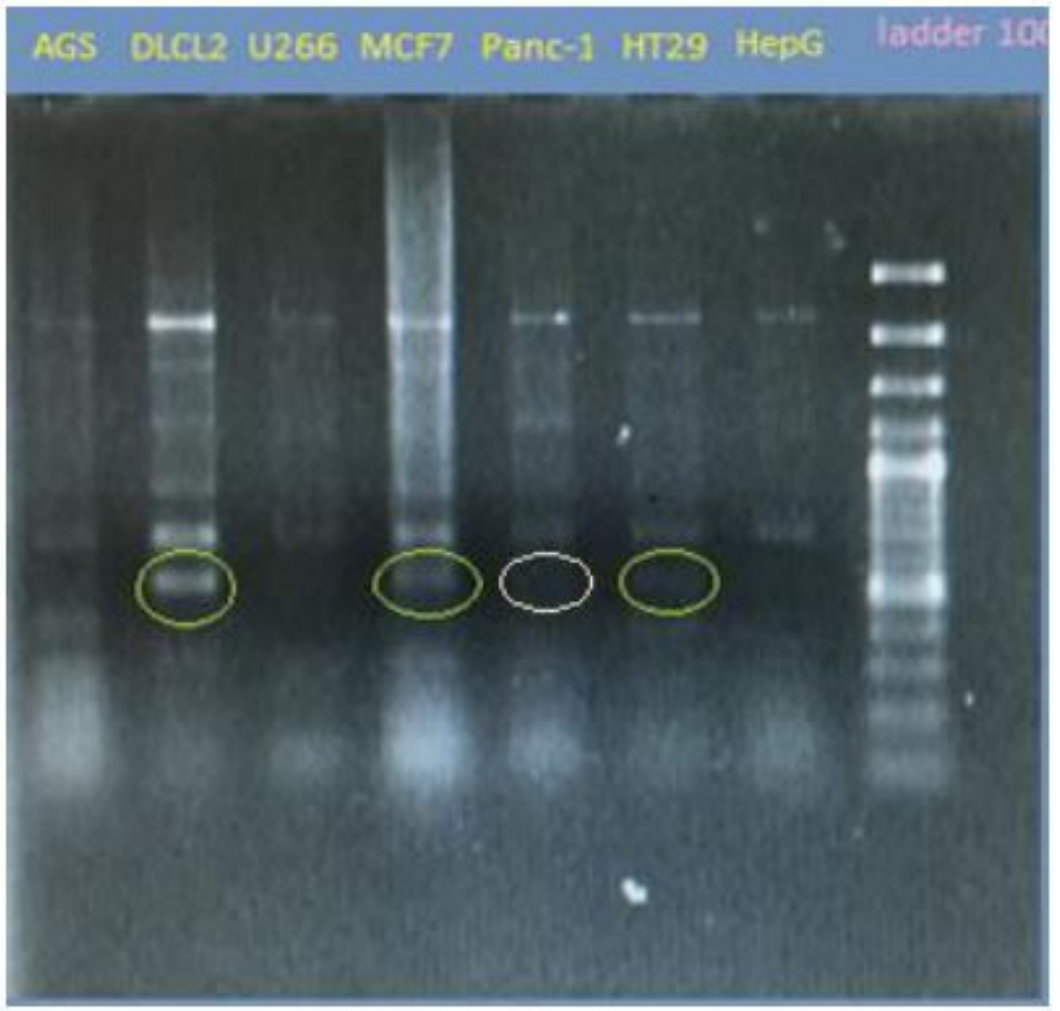

\section{Figure 3}

bcl2 translocation shows MCR break point bands in AGS (stomach cancer cell line), DLCL (diffuse large cell lymphoma), U266 (multiple myeloma), MCF7 (Breast Cancer), Panc-1 (pancreatic cancer), HT29 (colon cancer) and Hep G2 (liver cancer). Yellow circles show the corresponding MCR bands. The result is congruence with Bicelin anti-cancer activity and its specificity (figure 2). 

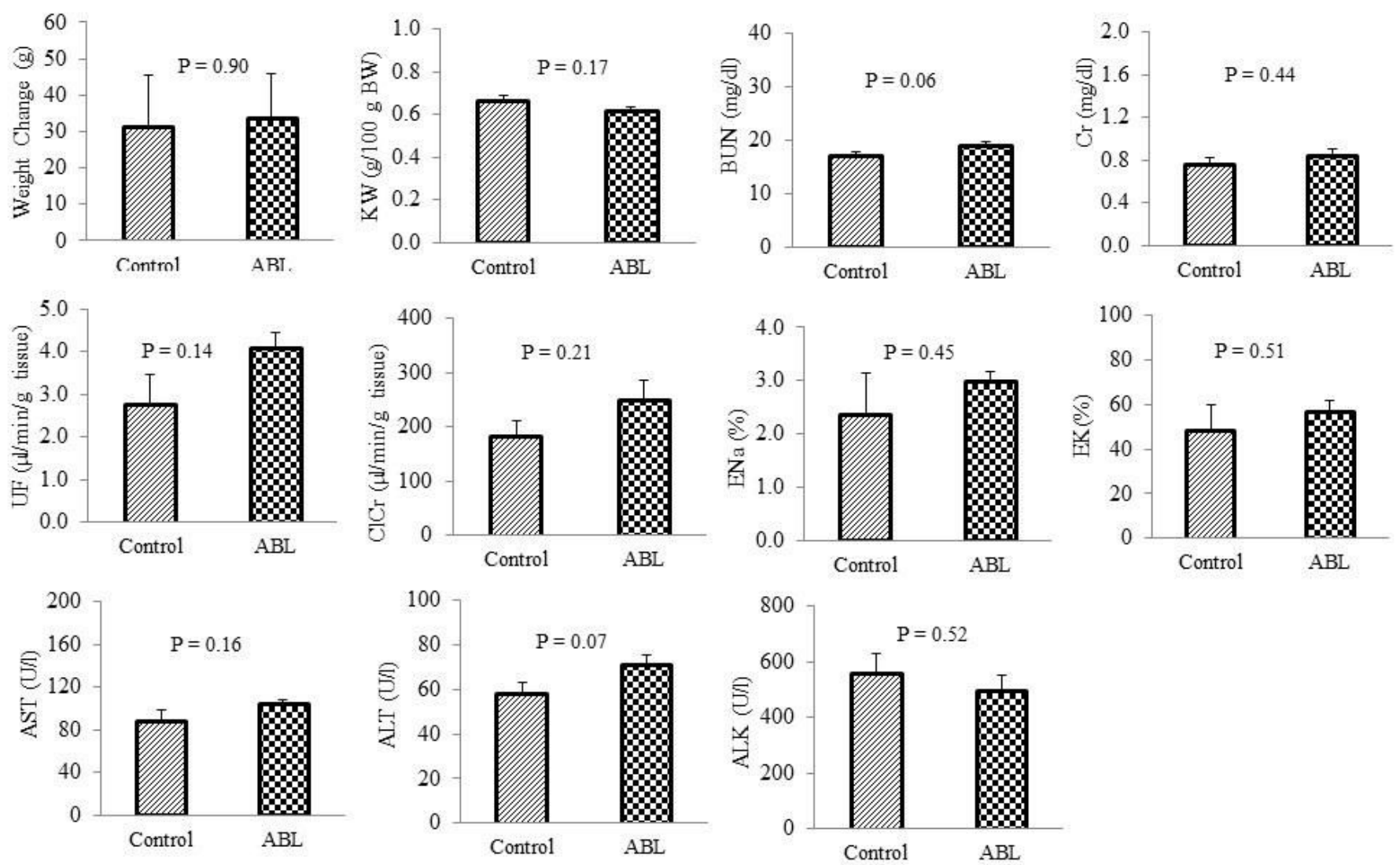

\section{Figure 4}

The weight change and kidney weight (KW), serum levels of blood urea nitrogen (BUN), creatinine ( $\mathrm{Cr}$ ), aspartate aminotransferase (AST) alanine aminotransferase (ALT) and anaplastic lymphoma kinase (ALK), and urine flow (UF), $\mathrm{Cr}$ clearance (ClCr), and sodium (ENa) and potassium (EK) excretion fraction in two groups of animals treated with vehicle (control) and ABL. No significant differences were observed between the two groups measuring the above parameters. 

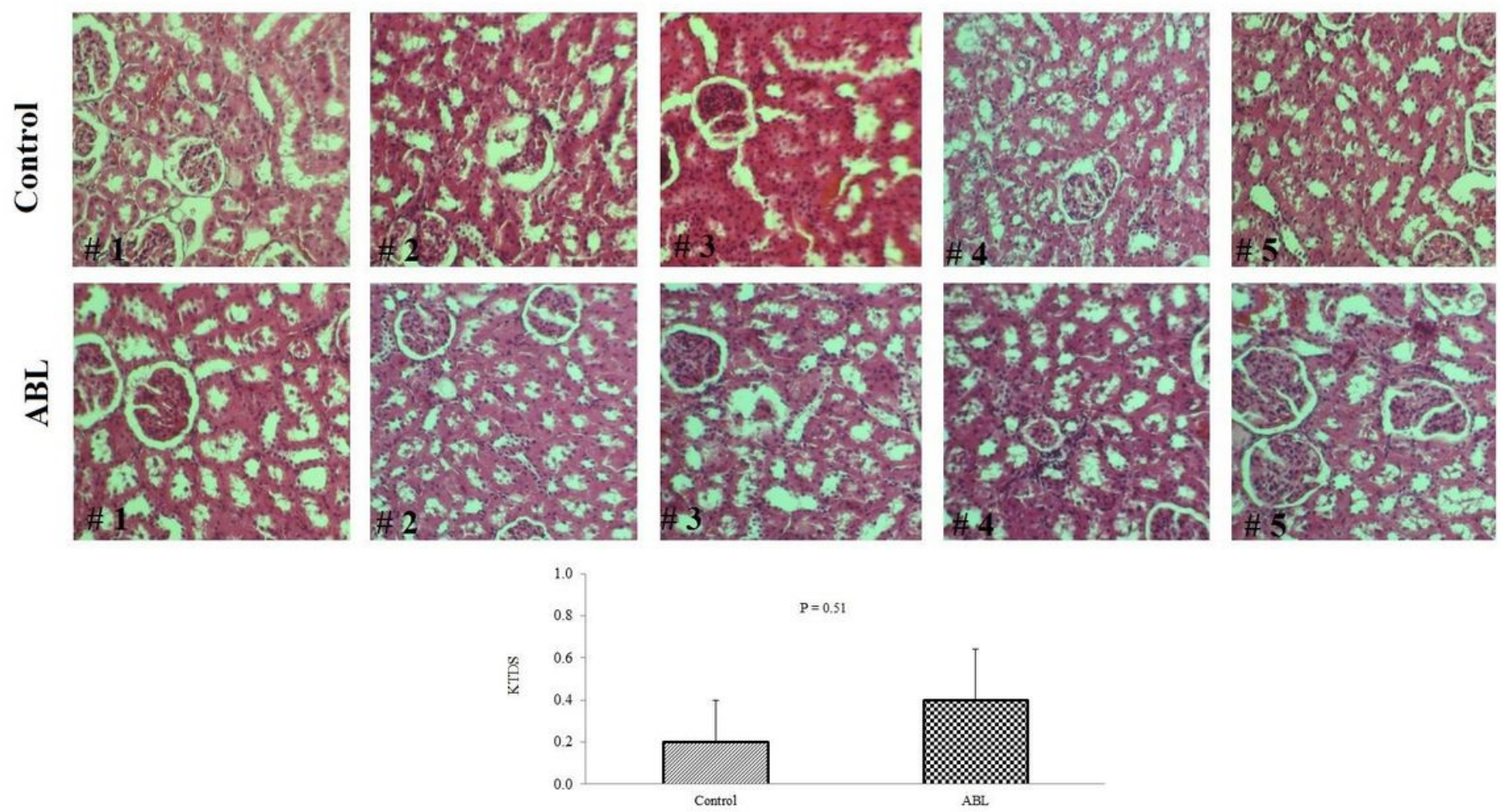

Figure 5

The kidney tissue images (100X) and kidney tissue damage score (KTDS) in two groups of animals treated with vehicle (control) and ABL24. No difference in tissue injury was seen between the animals of both groups. No significant difference also was observed between the groups related to KTDS. The number in the pictures indicates the five animals in each group. 

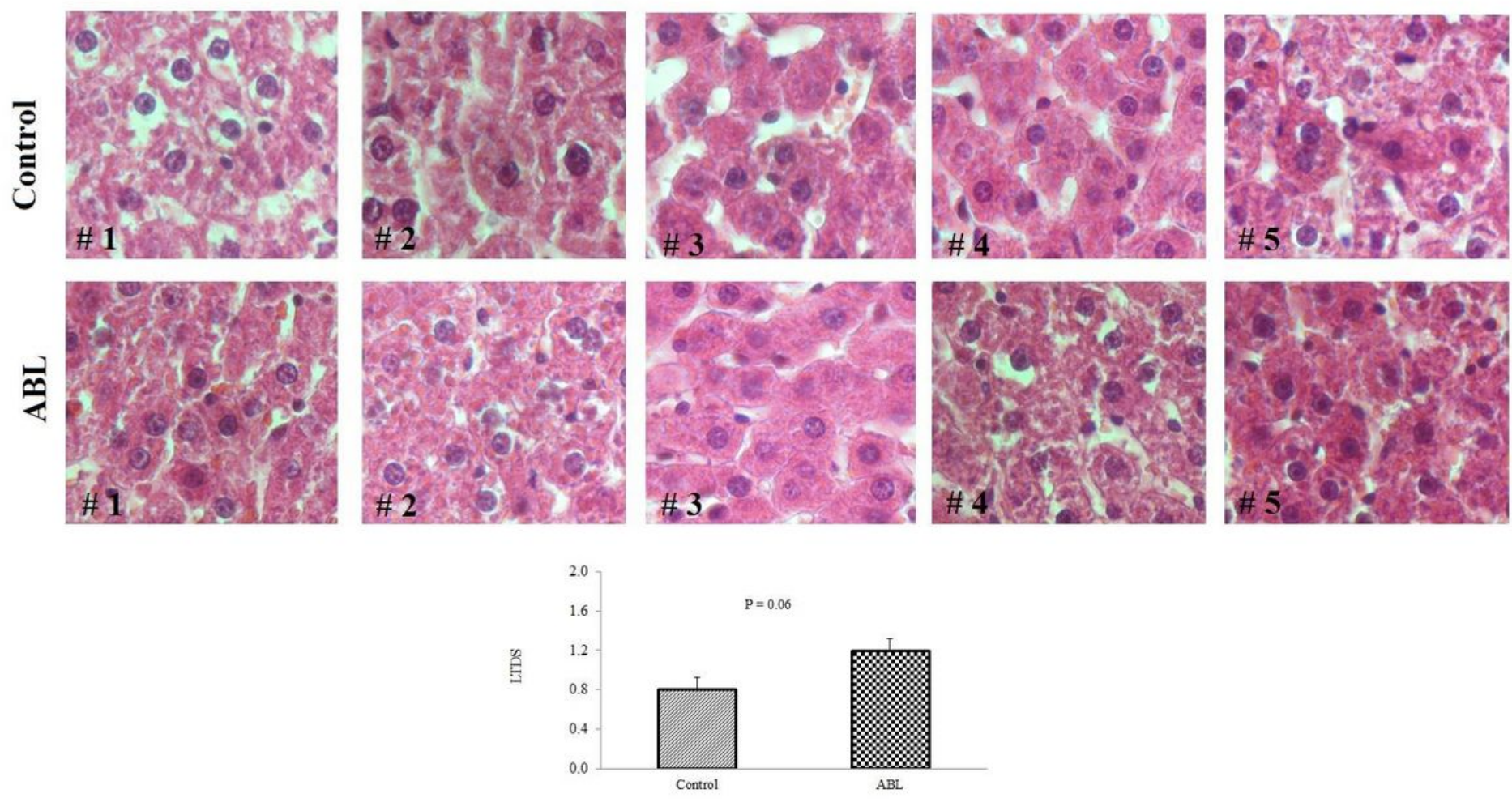

\section{Figure 6}

The liver tissue images (400X) and kidney tissue damage score (LTDS) in two groups of animals treated with vehicle (control) and ABL24. No difference in tissue injury was seen between the animals of both groups. No significant difference also was observed between the groups related to LTDS. The number in the pictures indicates the five animals in each group.

\section{Supplementary Files}

This is a list of supplementary files associated with this preprint. Click to download.

- ARRIVEChecklist.pdf

- Bicelinpathology.xlsx

- Table.docx.pdf 